\title{
The Impact of Talent Management Strategies on Bank Performance in Jordanian Commercial Banks
}

\author{
Adnan M. Rawashdeh ${ }^{1}$ \\ ${ }^{1}$ The University of Jordan, Jordan \\ Correspondence: Adnan M. Rawashdeh, The University of Jordan, Jordan. E-mail: adnanrawa@yahoo.com
}

Received: Sep. 13, 2018

Accepted: Sep. 25, 2018

Online Published: November 16, 2018

https://doi.org/10.5539/mas.v12n12p49

URL: https://doi.org/10.5539/mas.v12n12p49

\begin{abstract}
Talent management is very significant to the survive of firms in highly competitive business environment today. it refers to the application of needed employees for a firm and the programs to fit those needs and it combines employee knowledge, skills, attitude, values, competencies and work preferences. The explosive growth of Jordanian banking sector has led to an urgent need to develop talent management strategies as a means of boosting bank performance. The purpose of this study was to investigate the impact of talent management strategies on bank performance in Jordanian commercial banks. The design of the study has quantitative approach. Primary data was obtained by questionnaire instrument. The respondents in this study were line managers and HR managers in head admistrations. The number of population was 120 respondents. Random sampling was used in the study. 101 completed questionnaires were analyzed as a final sample. Three hypotheses have been developed through literature review and tested using descriptive analysis and independent t-sample test performed by SPSS. The results indicate a positive association of attracting, developing and retaining talents with bank performance. bank management is advised to keep developing the attracting mechanism they have applied in order to cope with the changes in the business environment and stay competitive. Also, its advised to maintain developing the motivation system according to the labor market conditions and competitivnes in order to retain talented staff and to avoid labor turnover. As it should concentrate on the rewards mechanizim as a main key to retain talents. future studies recruiting larger sample sizes are needed. Furthermore, prospective studies should effectively compare Jordanian bank performance with other banks in the Middle East based on these variables.
\end{abstract}

Keywords: Jordan, banks, talent manageemnt, performance, strategies

\section{Introduction}

Recent goals that are prioritized by business firms are primarily inclusive of creating sustainable competitive advantage and stimulating firm performance. Fixed assets, land and capital are no longer key resources for firms to maintain competitive in the current changing environment (Mathimaran \& Kumar, 2017). Money, machines, and most significantly people, are evolving into valuable assets which can be used to compete successfully and outperform competitors (Rawashdeh, 2018). Various values in respect to individuals working in business firms; at some points in time they were referred to as the key resource of production and at other times, they would be called the human resources of the firm(Bhatti, 2014). Recent developments consider human resources as the most valuable asset within the framework of the firm. Specifically, they are now perceived as the talent working within the firm; thereby, the practice of talent management came into being (King, 2015; Kehinde, 2012). Talent management has been defined as a systematic process of identifying, recruiting, developing, retaining and rewarding talented people (CIPD, 2015; Garge \& Rani, 2014; Beheshtifar, Nasab \& Nekoie, 2012). It has the ability to create firms that are more intelligent, flexible and competent as compared to their counterparts, through the application of strategies that concentrate on attracting, developing, retaining talented employees and directing their best efforts to cooperate within the firm's resource bundle (Caplan,2014). Also, it can potentially consolidate firm performance and create a competitive advantage because talented people are an intangible asset, whose depth and diversity cannot be imitated or replicated by competitors (Sahoo, 2015). Thus, to create positive performance, firm management is invited to attract, develop and retain talented individuals who are capable of achieving this objective successfully (Kronz,2014; Rawashdeh \& Al-Adwan, 2012).

Jordanian banking sector is considered as the most important service sector affecting Jordan economy, with a rapid growth and contribution to the gross domestic product (GDP), that is $80 \%$ services and $20 \%$ goods. The 
transformation of the production-based world economy into a knowledge-based one in addition to the global economic crisis had posed several challenges to Jordan economy. To mitigate the risk posed to their banks, Jordanian banking managements declared a new policy stating a proactive approach with respect to attracting, developing and retaining talented employees. Additionally, bank managements have emphasized on achieving positive performances through using their talented employees as a strategic asset, at a time when the global economy is seeing a decline. Based on the aforementioned, the central aim of this study was to investigate the impact of talent management strategies in the form of attraction, development and retention on the performance of Jordanian commercial banks.

\section{Literature Review}

The concept of talent management has been discussed in literature since the 1990s (Shaemi, Allemah \& Bajgerani, 2011). Since then, it has been widely discussed by managements, practitioners, consultants and academics. It combines employee knowledge, skills, attitude, values, competencies and work preferences (King, 2015). The practice of talent management gained momentum due to the increased awareness of the influence of talents within firms (FakhrElDin, 2013). Talent management refers to the expectations made of needed employees for a firm and those planning to fit those needs. It is essential for firms to carry out their goals successfully (Taleghani et al,2013). Organizations must hire talented people who are both proactive and reactive to a turbulent business environment (Rawashdeh,2018). They must also identify the required skills, knowledge and competences needed to achieve their goals and instill them into their workers (Bhatti, 2014). Despite the increasing war for talent, there seems to be no consensus regarding the exact definition and framework of talent management (Burkus \& Osula, 2011). Additionally, the scope and model of talent management is widely vary among scholars pertaining to this context. In this regard, a survey by CIPD (2006) found that $51 \%$ of human resource executives applied talent management practices; however, only $20 \%$ of them agreed on a formal definition of talent management. Talent management may involve human resources in addition to organizational development practices with respect to attracting, developing and retaining highly qualified individuals for future leader-manager opportunities in the firm (ALDamoe et al, 2012). It can be an implementation of integrated systems or strategies designed to stimulate firm performance through supporting improved processes for attracting, developing, retaining and optimizing employees with the skills and competencies to fit current and future business needs (Iqbal et al, 2013; Cappelli, 2008). Several scholars have investigated three talent management practices: talent attracting, talent developing, and talent retaining, that have a positive effect on firm performance (King, 2015; FakhrElDin, 2013; Kehinde, 2012; Vaiman, Scullion \& Collings, 2012). In line with the literature, this study has also adopted the above three practices attracting, developing and retaining, as they fit its objective.

\subsection{Talent Attraction}

Talent attraction can be considered as a process of inviting individuals to apply for vacancy. It is composed of recruitment and selection, employer choice, employer branding and employee value proposition ( Kim et al, 2014 ). Recruitment and selection process requires firms to implement a specific criterion of choosing the best applicant who meets the job specification (Armstrong, 2012). Recruitment of talent people is indicative of the first practice of talent management strategy. The talent people is a collection of individuals with differentiated skills who become a source of future senior executives for firm (Kehinde, 2012). There are two sources to create a talent people, where the first is internal and the second one is external. The internal source is considered as the best way of creating a talent individuals, as people already possess the knowledge of running businesses and are also capable of easily managing the vacated position. However, if there is a need for radical changes or culture renewal, the external source is the best fit (Baum \& Kabst, 2013). Employer branding is indicated as a very useful strategy for attracting talents. It is the practice of promoting the brand name of a firm to distinguish it from competitors in the eyes of customers. It gives the organization a major edge in increasingly completive market if managed effectively (Burkus \& Osula, 2011). Employee value proposition is known as a collection of offerings provided by a firm in return for employee performance at workplace. It fosters the loyalty and parity of personnel as well as employee satisfaction (Ariss, 2014).

\subsection{Talent Development}

Talent development is considered as one of the significant stages of the talent management process (Mathimaran \& Kumar, 2017). Firms may adopt several talent development strategies to improve their employees' skills, competencies, attitude and knowledge with the intention of creating positive performance (Rathod, 2014). Today, organizations should focus on creating a learning culture that enables their objectives to be met (Bhatti, 2014). However, the learning policy will be affected by the learning culture. Learning policy refers to the management understanding of organizational and employee learning and development(Sahoo, 2015). Organizations may 
produce a learning organization through the effective practices of their employees pertaining to learning and development (Armstrong, 2012). Training and development, mentoring, coaching and succession planning are all tools for creating a learning organization. These tools are considered to be talent management practices that may lead to positive firm performance (Farrukh \& Waheed, 2015).

\subsection{Talent Retention}

Currently, employee retention is considered as one of the primary tasks that poses a significant challenge to many organizations (Fayyazia et al, 2015). It is a strategic weapon for firms to maintain competitivity. Human resource department implements different talent management strategies with the purpose of maintaining a high retention rate (Paillé, 2014). Retention talents may be inclusive of policies, practices and strategies that are adopted by organizations to satisfy their talents and prevent them from leaving the organization (Bangwal \&Tiwari, 2015). Talent turnover has a positive influence on organizational performance, as it incurs direct and indirect cost to the organization (Burbach, 2010). Numerous scholars such as Masri\& Jaaron (2017) argued that retention can be improved when talents are motivated by monetary or non-monetary rewards, which may support their loyalty for the firm. The monetary rewards are viewed by talents as a key tool to retain them. For example, the salary should not be recognized as a sum of many, but as a package of remunerations needed to satisfy talent retention (Kehinde, 2012). Therefore, all business organizations are invited to adopt effective motivation mechanism to maintain their talented employees. There is a de facto recognition that motivated employees are loyal, committed, contented, dedicated, and enthusiastic (San et al, 2012).

\section{Research Hypotheses}

Based on the literature review, the following hypotheses have been provided.

$\mathbf{H}_{1}$ : Attracting talent has a positive impact on bank performance in Jordanian commercial banks.

$\mathbf{H}_{2}$ : Developing talent has a positive impact on bank performance in Jordanian commercial banks. .

$\mathbf{H}_{3}$ : Retaining talent has a positive impact on bank performance in Jordanian commercial banks. .

\section{Research Method}

This study employed a quantitative approach for investigation. A survey in the form of a questionnaire was used to collect primary data from the research sample. The key respondents were line managers and HR managers in the head administration, as they have the best knowledge of talent management practices in thier banks. Information pertaining to the banks was obtained from the Jordanian Central Bank Annual Report. The population of this study consisted of 13 Jordanian commercial banks. As many as 120 questionnaires were submitted directly by the researchers to bank sample. A total of 107 questionnaires were received until the end of survey and after deep investigation a number of 6 questionnaires were found unfit for analysis. Therefore, a total of 101 questionnaires were used in the analysis process, which was considered as the study sample, giving a response rate of $84 \%$ which is considered highly satisfactory. The size of the study sample was relatively small. Consequentially, the researcher adjusted the study data analysis strategy by using the best valuable statistical methods such as means, standard deviation, and Cronbach's alphas to deal with such small sample sizes. Stratified sampling was applied in this study and the sample size has been chosen according to the population of bank. Following this, random selection of the sample was carried out. The data was then analyzed using Statistical Package for Social Science (SPSS 20). The questionnaire was divided into three segments. Segment A captured information about the respondents, such as their organizational tenure, education, age, gender, and length of service in bank. Segment B captured information with respect to the independent variable, in the form of talent management practices. As stated earlier, these were composed of talent attracting, talent developing and talent retaining practices. Segment $\mathrm{C}$ tackled questions pertaining to the dependent variable, in the form of bank performance dimensions. These were inclusive of customer complaint, market share, net profit, increased in total sales, employee commitment, turnover rate and employee satisfaction. In answering the questionnaire, the respondents were asked to indicate their responses to the questions on a five-point Likert scale ranging from 1 (Strongly Disagree) to 5 (Strongly Agree). The items used in this study were adapted from different studies (Bhatti, 2014; King, 2015; FakhrElDin, 2013; Kehinde, 2012; Vaiman, Scullion \& Collings, 2012). Cronbach's Alpha was used to test the internal consistency of the instrument, the values ranged from $0.70-0.92$. The reliability of all constructs of the instrument is above $70 \%$, and the total reliability of the survey is above $84 \%$ which is considered as excellent (Vogt., 1999).

Table 1. Scale determine the relative importance of the mean. 


$\begin{array}{cc}\text { Low } & 2.33 \text { and less } \\ \text { Medium } & 2.34-3.67 \\ \text { High } & 3.68-5\end{array}$

These categories were derived according to the following equation:

Interval length $=($ highest weight - lowest weight $) /($ three levels $)=(5-1) / 3=1.33$

Table 2. The mean and standard deviation for the survey items in commercial banks.

\begin{tabular}{cccc}
\hline Category & Mean & SD. & Level \\
\hline Attraction & 3.52 & 1.16 & Medium \\
Developing & 2.62 & 0.98 & Medium \\
Retention & 4.16 & 1.22 & High \\
T.M practices & 3.433 & 1,120 & Medium \\
Customer complaint & 3.24 & 1.08 & Medium \\
Market share & 3.16 & 1.27 & Medium \\
Turnover rate & 2.27 & 0.83 & Low \\
Employee satisfaction & 4.28 & 0.72 & High \\
Net profit increased by sale & 4.11 & 1.24 & High \\
Bank performance & 3.412 & 1.028 & Medium \\
\hline
\end{tabular}

Table 3. The correlation between survey items.

\begin{tabular}{ccccc}
\hline & Attraction & Development & Retention & Bank performance \\
\hline Attraction & 1 & $0.63^{* *}$ & $0.51^{* *}$ & $0.66^{* *}$ \\
Development & & 1 & $0.54^{* *}$ & $0.68^{* *}$ \\
Retention & & & 1 & $0.74^{* *}$ \\
Bank performance & & & 1 \\
\hline
\end{tabular}

**. Correlation is significant at the 0.01 level (2-tailed).

Table 4. Multiple linear regression analysis to test the relationship between T. M strategies and bank performance

\begin{tabular}{cccccccccc}
\hline Variable & Adjusted $\mathbf{R}^{\mathbf{2}}$ & $\mathbf{R}^{\mathbf{2}}$ & $\mathbf{F}$ & $\mathbf{S i g}(\mathbf{f})$ & $\mathbf{T}$ & $\mathbf{S i g}(\mathbf{t})$ & $\boldsymbol{\alpha}$ & $\boldsymbol{\beta}$ & Decision \\
\hline Attraction & & & & & 4.04 & 0.002 & & 0.340 & Supporting \\
Development & 0.810 & \multirow{2}{*}{0.740} & \multirow{2}{*}{86.2} & 0.000 & 4.58 & 0.000 & 0.68 & 0.320 & Supporting \\
Retention & & & & & 4.64 & 0.006 & & 0.402 & Supporting \\
\hline
\end{tabular}

\section{Results and Discussion}

The data was analyzed through descriptive statistical methods with mean, standard deviation, percentage, Pearson correlation coefficient, T-test and regression. The above-mentioned findings are in conformity. The results of descriptive statistics indicated general agreement of the respondents with respect to talent management strategies. The mean values ranged from 4.16 , which was the highest, to 2.62 , which was the lowest. The results for the retaining strategy indicated highest conformity, where the mean was 4.16 and the standard deviation was 1.22 . The developing strategy was a lower indicator, exhibiting a mean of 2.62 and a standard deviation of 0.98 . The highest conformity was shown by bank performance with employee satisfaction, as mean 4.28 and a standard deviation of 0.72 . The turnover rate was the lower indicator showing a mean of 2.27 and a standard deviation of 0.83 . The mean scores and standard deviation reflected conformity of respondents' perception about these items.. The results of correlation coefficient in table 3 indicate support for all the hypotheses. The results for retaining strategy indicated 
the strongest correlation $(p=0.74)$, where the attracting strategy indicated the lowest correlation $(p=0.66)$. To test the first hypothesis, the correlation coefficient in table 3 was 0.66 , suggesting a high positive association of attracting strategy with bank performance. The T-value in table 4 is 4.04 , indicating that there is a significant relationship between the attracting strategy and bank performance, as the value of the significance level $(0.002)$ related to T-value was less than 0.05 . This positively significant relationship means that the bank management has used a rigorous mechanism for attracting talented employees and the best applicants were posted to fill vacancies. This mechanism is considered as a significant criterion for creating and sustaining positive bank performance (Kim et al, 2014). The second hypothesis was tested; it was seen that the correlation coefficient in table 3 was 0.68 . This was suggestive of a high positive association between the developing strategy and bank performance. The T-value in table 4 is 4.58 , which indicates that there is a significant relationship between the developing strategy and bank performance, since the value of the significance level $(0.000)$ related to T-value was less than 0.05 . suggesting the presence of the relationship. The statistical significance of hypothesis 2 confirms that bank management has invested enough money in the form of training and development programs in order to provide employees with the required skills, knowledge and education that may help in achieving bank objectives. De facto, there is a golden rule states if employees well developed they can provide outstanding firm services and meet roll expectations. developed employees are considered as the most loyal, committed, dedicated, enthusiastic, and contented employees (San et al, 2012). To test hypothesis 3, correlation coefficients in table 3 was (0.74) suggested a high positive association of retaining strategy with bank performance. The $T$ value in table 4 is (4.64) indicates that there is a significant relationship of retaining strategy with bank performance as the value of the significance level (0.006) related to $T$ value was less than 0.05 suggesting the presence of the relationship. This statistical significance explains that bank management has viewed retention strategy as a strategic tool to maintain competitive in the marketplace. the high mean level of employee satisfaction 4.28 confirms the support of bank manageemnt to the talents retention and preventing them from voluntarily resignation or leaving the bank to another one. Also, the low turnover rate that indicated 2.27 in mean level confirms that employees are happy and satisfied with working for the bank. Generally speaking, retaining top managers begins with posting the right talent in the first line position. Line staff will be strong contributors -workers who are valuable and firms need to retain. Likewise, personnel who are suitable for the job and perform well will need to stay with the firm. During the recruitment and selection process, firms may specify potential talents by analyzing the qualifications, experience, needed skills and comparing them to the applicant profiles and resume. The process can be effective to attract the potential talent if the hiring managers have a clear perception of the needed skills and strategic objectives of the department and the firm. And this may help them in selling the position to the best talent (Garg \& Rani, 2014). Training and development programs may increase retention as they meet the specific needs of the personnel. Those needs can be met when the information offered to employees is perceived as valued, useful and desirable, As the main key to retain employees is the rewards both psychological and financial that firms should concentrate on (Haider et al, 2015). Finally, bank management is advised to keep developing the attracting mechanism they have applied in order to cope with the changes in the business environment and stay competive. Also, its advised to maintain developing the motivation system according to the labor market conditions and competitiveness in order to retain talented staff and to avoid labor turnover. The above findings are in conformity with (Mathimaran \& Kumar, 2017; Karunathilaka et al, 2015; King, 2015; FakhrElDin, 2013; Venkateswaran, 2012; Kehinde,2012; Vaiman et al, 2012; Senthilkumar \& Kumudha, 2011) results.

\section{Conclusion}

The study revealed that talent management is very significant to the survivor of the banking sector in the highly competitive business environment today. It's of value that banks should take into consideration the issue of talent management, the fact that mobility of talents is very high today cross national and international border mad talent management such a pivotal issue to the business organizations especially those operating in developing countries. The objective of this study was to test the relationship between talent management practices, attracting, developing, retaining and bank performance in Jordanian commercial banks. Previous studies asserted a positive and significant effect of talent management practices on bank performance, and this study empirically confirmed that there is a linear relationship between talent management strategies (attracting, developing, retaining) and bank performance in Jordanian commercial banks. Bank management is advised to keep developing the attracting mechanism they have applied in order to cope with the changes in thje business environment and stay competitive. Also, its advised to maintain developing the motivation system according to the labor market conditions and competitivness in order to retain talented staff and to avoid labor turnover. As it should concentrate on the rewards mechanizim as a main keey to retain talents. The major limitation of this study is that the study asked for perceived data about actual talent management practices and performance measures, but the respondents might have given desired data, which made their banks sound good, as all of the respondents were line manegers and human resource 
managers. The size of the study sample was relatively small. Consequentially, the researcher adjusted the study data analysis strategy by using the best valuable statistical methods such as means, standard deviation, and Cronbach's alphas to deal with such small sample sizes. future studies recruiting larger sample sizes are needed. furthermore, prospective studies should effectively compare Jordanian bank performance with other banks in the Middle East based on these variables

\section{References}

ALDamoe, F. M. A., Yazam, M., \& Ahmid, K. B. (2012). The mediating effect of HRM outcomes (employee retention) on the relationship between HRM practices and organizational performance. International Journal of Human Resource Studies, 2(1), 75-88. https://doi.org/10.5296/ijhrs.v2i1.1252

Ariss, A. A., Cascio, W. F., \& Paauwe, J. (2014). Talent management: Current theories and future research directions. Journal of World Business, 49, 173-179. http://dx.doi.org/10.1016/j.jwb.2013.11.001

Bangwal, D., \& Tiwari, P. (2015). Green HRM - A way to greening the environment. IOSR Journal of Business and Management, 17(12), 45-53. https://doi.org/10.9790/487X-171214553

Baum, M., \& Kabst, R. (2013). How to attract applicants in the Atlantic versus the Asia-Pacific region: A crossnational analysis on China, India, Germany, and Hungary. Journal of World Business, 48, 175-185. http://dx.doi.org/10.1016/j.jwb.2012.07.002

Beheshtifar, M., Nasab, Y., \& Nekoie, M. (2012). Effective Talent Management: A Vital Strategy to Organizational Success. International Journal of Academic Research in Business and Social Sciences, 2(12), 227-234.

Bhatti, N. K. (2014). Humanresource management factors and service recovery performance in Malaysian life insurance industry. European Journal of Training and Development, 38(6), 524-552. https://doi.org/10.1108/EJTD-07-2013-0078

Brah, S. A., \& Ying Lim, H. (2006). The effects of technology and TQM on the performance of logistics companies. International Journal of Physical Distribution \& Logistics Management, 36(3), 192-209. https://doi.org/10.1108/09600030610661796

Burbach, R., \& Royle, T. (2010). Talent on demand? Talent management in the German and Irish subsidiaries of a US multinational corporation. Personnel Review, 39(4), 414-431. https://doi.org/10.1108/00483481011045399

Burkus, D., \& Osula, B. (2011). Faulty Intel in the War for Talent, Replacing the Assumptions of Talent Management with Evidence-Based Strategies. Journal of Business Studies Quarterly, 3(2), 1-9.

Caplan, J. (2014). Thinking differently about talent development. Human Resource Management International Digest, 22(2), 42 - 45. https://doi.org/10.1108/HRMID-03-2014-0034

Cappelli, P. (2008). Talent Management for the Twenty-First Century. Harvard Business Review, 86(3), 74-81.

CIPD. (2015). Align Talent with your Business Strategy to Gain Competitive Advantage, Managing Talent Conference and Workshop, UK: Chartered Institute of Personnel and Development.

Conger, J. Fulmer, R. (2003). Developing your leadership pipeline. Harvard Business Review, 81(12), 76 - 85.

FakhrElDin, H. (2013) The Effect of Talent Management on Organizational Success: A Comparative Study in the Petroleum Sector in Egypt. Journal of US-China Public Administration, 10(4), 358-367.

Farrukh, M., \& Waheed, A. (2015). Learning Organization and Competitive Advantage - An Integrated Approach. Journal of Asian Business Strategy, 73-79. https://doi.org/10.18488/journal.1006/2015.5.4/1006.4.73.79

Fayyazia, M., Shahbazmoradib, S., Afsharc, Z., \& Shahbazmoradic, M. R. (2015). Investigating the barriers of the green human resource management implementation in oil industry. Management Science Letters, 5, 101-108. https://doi.org/ 10.5267/j.msl.2014.12.002

Feng, J., Prajogo, D. I., Chuan Tan, K., \& Sohal, A. S. (2006). The impact of TQM practices on performance: A comparative study between Australian and Singaporean organizations. European Journal of Innovation Management, 9(3), 269-278. https://doi.org/10.1108/14601060610678149.

Fuentes, M. M. F., Montes, F. J. L., \& Fernández, L. M. M. (2006). Total quality management, strategic orientation and organizational performance: the case of Spanish companies. Total Quality Management \& Business Excellence, 17(3), 303-323. https://doi.org/10.1080/14783360500451358

Gardner, T. M. (2002). In the Trenches at the Talent Wars: Competitive Interaction for Scarce Human Resources. Human Resources Management, Wiley periodicals, 41, 225-237. https://doi.org/10.1002/hrm.10033 
Garg, D., \& Rani, K. (2014). Talent Management: Empirical Research Results. International Journal of Management and Commerce Innovations, 289-295.

Gebelein, S. (2006). Talent Management: Today's HR Departments do Much More Than Just hiring and Firing, Personnel Decisions International (PDI), Minnesota Business Magazine.

Hair, J. F., Anderson, R. E., Tatham, R. L., \& Black, W. C. (1998). Multivariate data analysis (5th ed.). Upper Saddle River, NJ: Prentice Hall.

Huarng, F., \& Chen, Y. T. (2002). Relationships of TQM philosophy, methods and performance: a survey in Taiwan. Industrial Management \& Data Systems, 102(4), 226-234.

Iqbal, S., Qureshi, T. M., Khan, M. A., \& Hijazi, S. T. (2013). Talent management is not an old wine in a new bottle. African Journal of Business Management, 7(35), 3609-3619

Kehinde, J. S. (2012). Talent Management: Effect on Organizational Performance. Journal of Management Research, 4(2), 178-186.

Kim, Y., Rowthwell, W. J., \& Penaloza, P. (2014). A strategic model for technical talent management: A model based on a qualitative case study. Performance Improvement Quarterly, 26(4), 93-121.

King, K. A. (2015). Global Talent Management: Introducing a Strategic framework and Multiple-Actors. Journal of Global Mobility, 273 - 288. https://doi.org/10.1108/JGM-02-2015-0002

Klein, K. (2004). Investigating the Use of Human Resource Management Best Practice in New Zealand Firms, Ota. Manage. Grad Review Journal, 2, 39-68.

Kronz, E. (2014). Acquiring and developing leaders on a global or multinational scale. Strategic HR Review, 13(6), 249 - 254. https://doi.org/10.1108/SHR-09-2014-0048

Masri, H. A., \& Jaaron, A. A. (2017). Assessing green human resources management practices in Palestinian manufacturing context: An empirical study. Journal of cleaner production, 143, 474-489. 10.1016/j.jclepro.2016.12.087

Messmer, M. (2006) Four Keys to Improved Staff Retention. Strategic Finance, 88(4), 13-14.

Paillé, P., Chen, Y., Boiral, O., \& Jin, J. (2014). The impact of human resource management on environmental performance: An employee-level study. Journal of Business Ethics, 121(3), 451-466.

Rathod, P. N. (2014). Talent management: A strategy for competitive advantage paripex. Indian Journalof Research, 3(12), 55-57.

Rawashdeh, A. M., \& karim Al-Adwan, I. (2012). The impact of human resource management practices on corporate performance: Empirical study in Jordanian commercial banks. African Journal of Business Management, 6(41), 10591-10595.

Rawashdeh, A. M. (2014). TQM as a source of bank performance and competitive advantage empirical study in Jordanian banking sector. European Scientific Journal, ESJ, 10(22). http://dx.doi.org/10.19044/esj.2014.v10n22p\%25p

Rawashdeh, A.(2018) Motivation application: the key to stimulating work productivity in jordanian private universities. Moderen Applied Scince, 12(10), 43-49. https://doi.org/10.5539/mas.v12n10p43

Rawashdeh, A. (2018). The impact of green human resource management on organizational environmental performance in Jordanian health service organizations. Management Science Letters, 8(10), 10491058.https://doi.org/ 10.5267/j.msl.2018.7.006

Sahoo, S. P. (2015). Strategic talent development interventions: an analysis. Industrial and Commercial Training, $47(1), 15-22$

San, O., Theen, Y., \& Heng, T. (2012). The reward strategy and performance measurement (evidence from Malaysian insurance companies). International Journal of Business, Humanities and Technology, 2(1), 211223.

Shaemi, A., Allemah, M., \& Bajgerani, A. (2011). Impact of Talent Management Strategies on Employees Emotional Intelligence in Isfahan Municipality. Interdisciplinary Journal of Contemporary Research in Business, 3(6), 229-241.

Sharma, B., \& Gadenne, D. (2002). An inter-industry comparison of quality management practices and performance. Managing Service Quality: An International Journal, 12(6), 394-404. 
https://doi.org/10.1108/09604520210451876.

Taleghani, G. R., Amini, S., Ghaffari, A., \& Dvsy, H. (2013). The relation between talent management and performance of faculty members. Journal of Public Management, 5(3), 83-102.

Vaiman, V., Scullion, H., \& Collings, D. (2012). Talent management decision making. Management Decision, 50(5), 925-941. https://doi.org/10.1108/00251741211227663

Vogt, W. P. (1999). Dictionary of statistics and methodology: a nontechnical guide for the social science, sage publication, thousand oak.

Way, S., \& Johnson, D. (2005). Theorizing About the Impact of strategic human resource management, Human Resource Management Review, 1(19), 1- 13. https://doi.org/10.1016/j.hrmr.2005.01.004

\section{Copyrights}

Copyright for this article is retained by the author(s), with first publication rights granted to the journal.

This is an open-access article distributed under the terms and conditions of the Creative Commons Attribution license (http://creativecommons.org/licenses/by/4.0/). 